or mud, are brought prominently under notice by a recent reported discovery in Wyoming. This is said to be nothing less than the disentombment of an entire skeleton of that stupendous Dinosaur known as the Brontosaur, in which not only is every bone in place, but an actual mould of the surface of the eye, formed in the sand upon which the creature lay, has been preserved in the solid rock.

Prof. Marsh's restoration of the Brontosaur-a creature 60 feet in length, walking on all fours, with an enormously long neck and tail, a disproportionately small head, and the bony substance of its backbone reduced to a mere shell and a honeycombed interior-has been long before the world. Less known, however, is his later reconstruction of the skeleton of one of the gigantic horned Dinosaurs from the Laramie Cretaceous, which he calls Triceratops; the skull and pelvis of which were referred to in an earlier number of NATURE. In this restoration the Professor has certainly succeeded in producing a most marvellous animal, although, so far as we see, the figure appears to be true to nature. It will be remembered that one of the most remarkable features in the skull of Triceratops (which in some specimens was upwards of 12 feet in length) is the production of the hinder regi on into a huge fan-like shield. the use and purpose of which it was at first a little difficult to understand. This is, however, explained by the restored skeleton, where we see this shield overlapping and protecting the first six vertebræ of the neck; to which additional strength was imparted by the bony union of several of them. In the shortness of its neck and the enormous size of its skull, Triceratops presents a striking contrast to Brontosaurus. Like the latter, however, it habitually walked on all fours; while in correlation with its massive skull its forelimbs were relatively stouter than in any other Dinosaur. In this respect it differs widely from its near ally, Stegosaurus, which, at least occasionally, walked in a bird-like manner; and since Triceratops ${ }^{\circ}$ is evidently a more specialized creature than Stegosaums, the suggestion arises that the former has undergone a retrograde development from a bipedal to a quadrupedal mode of progression. No attempt has yet been made to represent the position on the skeleton of the dermal bony armour with which many parts of the body of Triceratops were protected during life; the precise position of the various spines, knobs, and plates, which have been found in assnciation with the bones, being largely a matter of conjecture. The size in life of the restored example would be approximately some 25 feet in length by Io in height ; but these dimensions must have been exceeded by other specimens.

By the completion (so far as anything connected with fossils can be said to be complete) of our knowledge of the skeleton of Triceratops, we are acquainted with the bony framework of all the chief types of Dinosaurian reptiles at present known. These may be classed as the Sauropodous type, as represented by Brontosaurus; the Theropodous type, as represented by Megalosaurus and its allies; and the Ornithopodous modification, represented on the one hand by Iguanodon, and on the other by Stegosaurus, Triceratops, \&c.

In the contemporary publication to which we have referred some interesting suggestions as to the probable habits of these Dinosaurs are put forth, although how far they will meet with acceptation remains to be seen. Thus it is suggested that the honeycombed vertebræ of the Brontosaurs and their allies were filled with warm air from the lungs (which assumes that these reptiles were warm-blooded), by which means their bodies were partly floated when they wandered out of their depth in the sea shallows, from whence they stretched their long necks to crop the seaweed near the shore. Again, the long hind legs of the Hadrosaur (an ally of our Iguanodon) are considered to have enabled their owner to wade far out to sea in search of seaweeds growing on the oceanพо. I I 87 , VOL. 46 ] floor; while the armoured kinds, like Stegosaurus and Triceratops, are considered to have been essentially terrestrial.

As we have indicated, the great bulk of the collection is composed of Secondary reptiles and Tertiary mammals; and from their large size it is these which form its most striking feature. We most not omit to state, however, that it also contains the Toothed Birds from the Cretaceous of Kansas (of which our English collections do not at present possess a single bone), as well as hosts of teeth of Mesozoic mammals, although we have no definite information as to what proportion of these are the property of the State, and what belong to Prof. Marsh. Then, again, scattered among the trays and drawers more especially devoted to the remains of mammals and reptiles is an extensive collection of fishremains from Cretaceous and Tertiary strata, and especially from the Green River Eocene shales of Wyoming, most of which we believe to be at present totally undescribed.

Space prevents us from saying more as to the extent of this marvellous collection-a collection which, with others from the same regions, has done more in ten years to revolutionize our classifications, and to give us a definite knowledge of many groups of animals previously known by battered fragments, than would have resulted from half a century's work upon European materials. We may, however, conclude by offering our hearty congratulations to the Governments of the United States and to Prof. Marsh, who have succeeded, by the liberality of the one and the untiring energy of the other, in amassing this magnificent collection, which is now, for the first time, in a fair way to be exhibited in a manner befitting its value and importance. Prof. Marsh's magnificently illustrated monographs on the Toothed Birds and the Dinocerata are splendid examples of how a collection like this ought to be made known to the scientific world at large ; and we trust ere long to be able to welcome his long-promised volumes on the Dinosaurs and the Brontotheres, which will render its riches yet better known.

R. LYDEKKER.

\section{DYNAMO-ELECTRIC MACHINERY.}

THIS is the first part of a treatise dealing with dynamo-electric machinery and its applications, and comprises the theory and practical construction of dynamos and motors, and an account of instruments and methods of electrical measurement. Such subjects as the fusion and welding of metals by electricity and the transmission of power are reserved for a second part, to be issued in the autumn of the present year.

The author begins with a chapter entitled "Generalities regarding Dynamos," in which he discusses the early rudimentary magneto-machines of Pixii and Clarke, and the multipolar machines of the same class invented by Stöhrer and Niaudet, gives a general explanation of the self-excitation and action of series of shunt and compound dynamos, and describes the various typical forms of armature used in constant and alternating-current machines. In this part there is room for little novelty of treatment; the author could only endeavour to be impartially historical and clearly descriptive, and give as complete and useful an account of the more important examples of dynamo machinery as his space would admit of. In this Signor Ferrini seems to have succeeded very well. He does not weary his readers with descriptions of mere antiquities, but supplies only such a brief account of earlier forms as is sufficient to enable the reader to trace the evolution of the modern constant-current dynamo, with its beautiful balance and inter-relation of

x “Recenti Progressi nelle Applicazioni deiì Elettricità di Rinaldo Ferrini." Parte Prima: Delle Dinamo. (Milano: Ulrico Hoepli, r 802 .) 
parts, from the rudimentary, uneconomical, and violently periodic machine of twenty years ago, or to compare the powerful alternator of the present day with the ineffective and wasteful toy instrument, which used to figure in cabinets of apparatus and the older books on electricity.

Chapter ii. deals with magnetic induction, and chapter iii. with the induction of currents by the motion of conductors in a magnetic field. These extend over almost 100 pages, or about one-fourth of the whole volume, a space none too large for the subject, but perhaps a little out of proportion to that devoted to dynamo machinery, which is still further restricted by the allocation of fifty pages in chapter iv. to methods of measurement.

Signor Ferrini's treatment of the theoretical part of his subject seems on the whole marked by completeness and accuracy. He has evidently given careful attention to the late developments of magnetic research, and in his chapter on measurements has included most of the improvements recently made, such, for example, as the methods of measuring power, \&c., in the circuits of alternators and transformers which have been invented by Ayrton and others. No mention is made, however, of Blakesley's ingenious "split dynamometer" method for transformers, and determining the difference of phase of two alternating currents. Nor is the method (p. I7 I) of finding the true mean activity in an alternating current from the apparent activity attributed to its inventor, Prof. Ayrton.

We notice here a few points which have occurred to us in looking over this part of the book as perhaps calling for remark. First of all with respect to the definition of a uniform magnetic field given at p. 58 , it may be noticed that if the numerical value of the intensity of the magnetic force be the same at all points of a firite space, its direction must be the same at all points of the same space, and that the intensity cannot vary in magnitude from point to point without varying also in direction, and vice versô. This does not seem to be generally understood, at any rate it is common to define a uniform field as one for which the magnitude and the direction of the magnetic force are the same at every point. That the former implies the latter, and the latter the former, may be seen by considering a closed surface formed by a portion of a tube of force, in the field, intercepted between two equipotential surfaces. The cross-sections at the two ends must have the same area, since the magnetic force at each end is the same. Further, the lines must be straight, for if they be supposed curved, the portion of the tube may be taken so that it is concave on one side and convex on the other. The line-integral of magnetic force round a closed circuit, taken along the convex and concave sides and across the ends, vanishes. But nothing is contributed to it by the ends of the tube. Hence the magnetic force along the convex side must be on the whole less than that along the shorter concave side, which contradicts the supposed uniformity of magnitude of the field-intensity.

At p. 66 difference of potential, $V_{1}-V_{0}$, between two points is defined as the work which must be done against magnetic forces in carrying a unit magnetic pole from the point of lower to that of higher potential ; and at p. 74, where the field of a solenoid is considered, $-d \mathrm{~V} / d x$ appears as the force on a pole of strength $m$.

At p. 8I mention might have been made of the influence of mechanical stress and disturbance on the magnetization of iron observed by Lord Kelvin and others, and of the fact that very much higher permeabilities than the 2000 quoted from Rowland's experiments have been obtained by Ewing for soft iron subjected to molecular vibration produced by tapping.

The subject of hysteresis is dealt with at p. 9I, and again at p. 235 in the chapter on the construction of a continuous-current dynamo. In the latter place a proof is furnished of the well-known formula given by Warburg in $188 \mathrm{I}$ or $\mathrm{I} 882$, and a little later by Ewing, for the energy dissipated in a closed cycle of magnetization. In the course of that proof, to which in itself we take no exception, one or two statements are made which, if we have understood the author aright, are erroneous. It is stated that when the integral induction $\Phi$ through each turn of a magnetizing helix of $n$ windings, each carrying a current $c$, is increased by an amount $d \Phi$, a quantity of energy $=-n c d \theta(=-\sigma \mathbf{H} d \mathbf{B} / 4 \pi)$, where $v$ is the volume of the medium magnetized, $\mathbf{H}$ the field intensity and $\mathbf{B}$ the induction, both supposed uniform) is given out by the spiral and converted into heat. Now (the sign being left out of account) this is certainly the energy sent into the field from the battery or generator, but it is not the case that it is all converted into heat. The amount of energy spent in unit volume of the magnetized medium is $\mathbf{H} d \mathbf{B} / 4 \pi$, but of this $(\mathbf{H} d \mathbf{B}$ $+\mathbf{B} d \mathbf{H}) / 8 \pi$ goes to increase the electrokinetic energy, the amount of which per unit volume of the medium is BH $/ 8 \pi$. The total amount of energy spent per unit volume in the cycle of magnetization, otherwise than in increasing the electrokinetic energy, is therefore

$$
\frac{\mathbf{I}}{4 \pi} \int\left\{\mathbf{H} d \mathbf{B}-\frac{\mathbf{I}}{\mathbf{2}}(\mathbf{H} d \mathbf{B}+\mathbf{B} d \mathbf{H})\right\},
$$

the integrals being taken round the cycle. (It is to be noticed that this balance of energy may be negative, and in that case energy is taken from the field to make up the increase of electrokinetic energy. ${ }^{1}$ )

But for a closed cycle

$$
\int(\mathbf{H} d \mathbf{B}+\mathbf{B} d \mathbf{H})=0
$$

and hence the energy spent is

$$
\frac{1}{4 \pi} \int \mathbf{H} d \mathbf{B}
$$

This must have been dissipated, since the medium at the end of the cycle has returned to the same state as at first.

No affirmation can be made as to what becomes of the balance of energy, except with reference to a closed cycle.

Again, at p. 237 it is stated that if $\mathbf{H}_{1},-\mathbf{H}_{1}$, be limits of $\mathbf{H}$ corresponding to limits $\mathbf{B}_{1},-\mathbf{B}_{1}$ of $\mathbf{B}$,

$$
\int_{-\mathbf{H}_{1}}^{\mathbf{H}_{1}} \mathbf{H} d \mathbf{B}=\int_{\mathbf{B}_{1}}^{\mathbf{B}_{1}} \mathbf{B} d \mathbf{H} .
$$

This is certainly not correct, as may be easily seen by representing the integrals graphically, or by considering that taken round a closed cycle

since

$$
\int \mathbf{B} d \mathbf{H}=-\int \mathbf{H}_{\mathbf{H}} d \mathbf{B}
$$

$$
\int(\mathbf{H} d \mathbf{B}+\mathbf{B} d \mathbf{H})=\int d(\mathbf{B H})=\mathbf{o}
$$

for the cycle.

This error, a mere oversight no doubt, has appeared more than once in connection with this subject, and an erroneous demonstration founded on it and a mistaken identification of the energy dissipated with the electrokinetic energy, has been used by more than one writer,

The chapters on the "Continuous Current Dynamo," the "Dynamo in Action," and "Alternating Dynamos," are excellent in many respects. The subject is well and fairly comprehensively treated, and the very useful notion of the magnetic circuit has been employed throughout with good effect. Some well-known machines do not seem to be described, for example, the Victoria among

$$
\text { I See a paper by the writer in the Phil. Mag., December r } 890 \text {. }
$$

$$
\text { No. [187, vol. 46] }
$$


continuous-current machines, and the latest form of Mordey's alternator.

The inclusion of a larger number of thoroughly practical examples of dynamo specification and construction would also be an improvement.

On the whole, Signor Ferrini's book seems the outcome of an earnest endeavour to give an accurate and full account in moderate compass of an important and difficult subject. It will be more easy to judge of the full measure of the author's success when the work is completed. In any case the book seems likely to be a credit to Italian technical literature.

A. GRAy.

\section{MR. A. NORMAN TATE.}

$\mathrm{BY}$ the death of Mr. A. Norman Tate, F.I.C., Liverpool has lost one of her most prominent citizens and men of science. It is not only as an able analytical chemist that Mr. Tate will be missed by a large section of the public to whom his genial presence was familiar, but as a scientific teacher and pioneer of the technical education movement in Lancashire, his place is one that will not easily be filled. For some time past .Mr. Tate has had indifferent health, and has had to give up much of his active work in connection with the Society of Chemical Industry, of whose Publication Committee he was a member, and the numerous local and other learned societies to which he gave great aid. Latterly, symptoms of an ulcerous tumour in the stomach presented themselves, from which he died on the 22 nd instant.

Mr. Norman Tate was a native of Wells, Somerset, and came to Liverpool about thirty-five years ago, when he entered the laboratory of the late Dr. Sheridan Muspratt. He published several papers bearing on his early researches in the journals of the Chemical Society of London and the Royal Dublin Society. After acting for some years as chemist to the firm of John Hutchinson and Co., of Widnes, he commenced practice as an analyst in Liverpool, and became consulting chemist to several important local bodies and chemical manufactories. At that time the importation of petroleum from America was beginning, and on this subject Mr. Tate became an authority; one of his works, "Petroleum and its Products," being translated and re-published in France and Germany. For a time Mr. Tate superintended the working of oil refineries in the Isle of Man and in Flintshire, where he erected a manufactory for the production of coal and shale oils. In I870, Mr. Tate, in conjunction with Mr. James Samuelson, undertook the initiation of the Liverpool Science and Art Classes, which grew to be a great educational power in the city. As honorary principal, Mr. Tate had charge of these classes, besides giving lectures himself and teaching several of the classes in chemistry, botany, and general biology. $\mathrm{He}$ also instituted the Liverpool Science Students' Association, and the Liverpool District Science and Art Teachers' Association, of both of which bodies he was the first president, a post he also filled in the local Geological Association, Microscopical Society, Liverpool Section of the Society of Chemical Industry, and other institutions, contributing largely to their "Transactions." The "Proceedings" of the Liverpool Geological Society also contain many of his papers and memoirs. He discovered the presence of iserine in the decomposed greenstones of the Boulder Clay in the Valley of the Mersey, and showed that the black colour of certain sandstones in the trias in the neighbourhood of Liverpool is due to the grains being coated with peroxide of manganese.

Mr. Tate was an ardent supporter of every educational movement, especially in connection with science teaching, and his death, at the early age of fifty-six, will be much deplored by a circle of friends extending far beyond the limits of the city which he had made the chief scene of his labours.

O. W. J.

\section{THE BRITISH ASSOCIATION.}

FVERYTHING is now practically ready for the meet ing of the British Association, which begins next week, and promises to be in every way most successful. Many distinguished foreign men of science-among them Helmholtz, Cremona, and Sachs---are expected to be present. The arrangements made by the local committee we described last week.

In compliment to the President there will be a specially strong muster of geologists. We hear that a number of professors and others connected with the Geological Survey of France are coming. Baron von Richthofen and Prof. Credner will represent the geologists of Germany; Prof. Renard those of Belgium. There will be many other representatives from different countries in Europe and from America. The geological excursions will likewise form a prominent feature in the proceedings, and one of these is to be conducted by the President of the Association in person. The Prince of Monaco, well known for his scientific researches, intends to bring his deep-sea dredging vessel to Granton, and to read a paper on the results of his marine surveys; while two members of his scieritific staff will communicate papers on some of the natural history objects obtained by them. Already a large amount of hospitality has been organized, and the meeting bids fair to be as successful in a social as in a scientific way.

We have already announced that at the meeting of Section A. on Monday, August 8, a discussion on the subject of a national physical laboratory will be opened by Prof. Oliver J. Lodge, F.R.S.

A meeting of the Electrical Standards Committee will be held on Thursday, August 4. It is expected that Dr. von Helmholtz, Dr. Lindeck of the Berlin Reichsanstalt, and others interested in electrical measurements, will be present. A discussion will take place with a view to securing an absolute uniformity in the standards adopted in England and elsewhere. The following points will be considered:-(I) The value of the B.A. unit in ohms; (2) the specific resistance of mercury in ohms; (3) standardizing by the electrolysis of silver; (4) the electromotive force of a Clark cell ; (5) Report of the Committee for I892. It is proposed to take the report of the Committee in Section A. on Tuesday, August 9. The draft prepared by the secretary is formal ; but it is hoped that the discussion in the Committee may lead to some resolutions, which will be included in the report.

The proceedings of Section D. promise to be exceptionally interesting. The President's address will relate to some qualities of sensation, with special reference to colour sense. On Friday there will be a joint discussion with B. on chemical aspects of the action of Bacteria, which will probably be opened by Prof. Marshall Ward. On Monday there will be a discussion on some matters connected with sea-fishes and fisheries, in which the following will read short papers or take part:- Sir J. Gibson Maitland, Prof. M'Intosh, Prof. Ewart, Dr. Fulton, Prof. Herdman, Mr. E. Holt, Mr. R. Smith, Mr. G. Brook, \&c.

\section{NOTES.}

THE summer meeting of the Institution of Mechanical Engineers, to which we referred last week, began at Portsmouth on Tuesday, under the presidency of Dr. William Anderson, F.R.S. The president, council, and members were received by the Mayor, who cordially welcomed them to Portsmouth.

THE British Medical Association's sixtieth annual meeting was opened at Nottingham on Tuesday, the chair being occupied by Dr. W. Withers Moore. In his presidential address Dr. Moore dealt with the progress which has been made in surgery and medicine since 1857 , when the Association held its last meeting at Nottingham.

$$
\text { NO. I I } 87 \text {, VOL. 46] }
$$

